\title{
Unusual Presentation of Angiolymphoid Hyperplasia With Eosinophilia in a Thirty-Six-Year-Old Man
}

\author{
Kambiz Kamyab ${ }^{1}$; Farhad Malekzad ${ }^{2}$; Safoura Shakoei ${ }^{3}$; Maryam Ranjbar ${ }^{2, *}$ \\ ${ }^{1}$ Department of Dermatopathology, Razi Hospital, Tehran University of Medical Sciences, Tehran, IR Iran \\ ${ }^{2}$ Skin Research Center, Shohada-e Tajrish Hospital, Shahid Beheshti University of Medical Sciences, Tehran, IR Iran \\ 3 Department of Dermatology, Ziaian Hospital,International Campus,Tehran University of Medical Sciences, Tehran, IR Iran \\ ${ }^{*}$ Corresponding author: Maryam Ranjbar, Skin Research Center, Shohada-e Tajrish Hospital, Shahid Beheshti University of Medical Sciences, Tehran, IR Iran. Tel: +98-2122744392, Fax: \\ +98-2122744393, E-mail:adineh_82@yahoo.com
}

Received: April 5, 2015; Accepted: February 26, 2015

\begin{abstract}
Introduction: Angiolymphoid hyperplasia with eosinophilia (ALHE) is a benign slow-growing vascular proliferation characterized by dome-shaped violaceous papules or nodules. Although it is usually found in the head and neck, it is reported in liver, orbit, spleen, palate, bone, heart, blood vessels, parotid gland, and colon.

Case Presentation: We reported a 36-year-old man with ALHE lesion on penis and discussed the clinical and histopathological features. Conclusions: When we have any dermal or subcutaneous lesion on genitalia, we can consider ALHE in differential diagnosis.

Keywords: Angiolymphoid Hyperplasia with Eosinophilia (ALHE); Penis; Genitalia Vascular Lesion
\end{abstract}

\section{Introduction}

Angiolymphoid hyperplasia with eosinophilia (ALHE) is an uncommon, benign, slow-growing disorder of adults and is characterized by solitary or multiple intradermal or subcutaneous erythematous, violaceous, or brown papules, plaques, or nodules (1-4).

Recent reports on ALHE focus particularly on atypical sites such as the tongue, penis, and eyelids (2-6). Penis is an extremely rare site for ALHE lesions comprising less than 26 cases reported up to date (6). We reported a 36-year-old man with ALHE lesion on penis and discussed the clinical and histopathologic features.

\section{Case Presentation}

A 36-year-old circumcised male, presented with an asymptomatic, solitary, erythematous plaque on his penis for months with a history of gradual increase in the size of the lesion over six weeks. There was no history of other symptoms such as urinary symptoms or painful erections or any other sexual dysfunction.

Before being referred to our center, He had received empiric treatments with some antibiotics such as penicillin for two to three weeks with the diagnosis of sexually transmitted diseases (STD), but there was no response to them. Unfortunately, the patient did not know the detail of the names, dosing, and intervals of the previous nonspecific treatments.

There was no involvement of any other parts of his body and he was otherwise in a good health. His family and medical history were insignificant. In addition, he had no his- tory of alcohol consumption or cigarette smoking. In addition, the patient did not mention any history of trauma.

Physical examination revealed a solitary, erythematous, eroded, indurated plaque measuring about $7 \mathrm{~mm} \times 13$ $\mathrm{mm}$ over the lateral aspect of glans penis (Figure 1). The lesion was non-foul-smelling, non-tender, and non-friable, and there was no bleeding on manipulation. In addition, the lesion was covered with scant yellowish slough. The examination of his inguinal lymph nodes revealed no significant lymphadenopathy. His general physical examination was quite normal and there was no associating lesions on other sites of the skin.

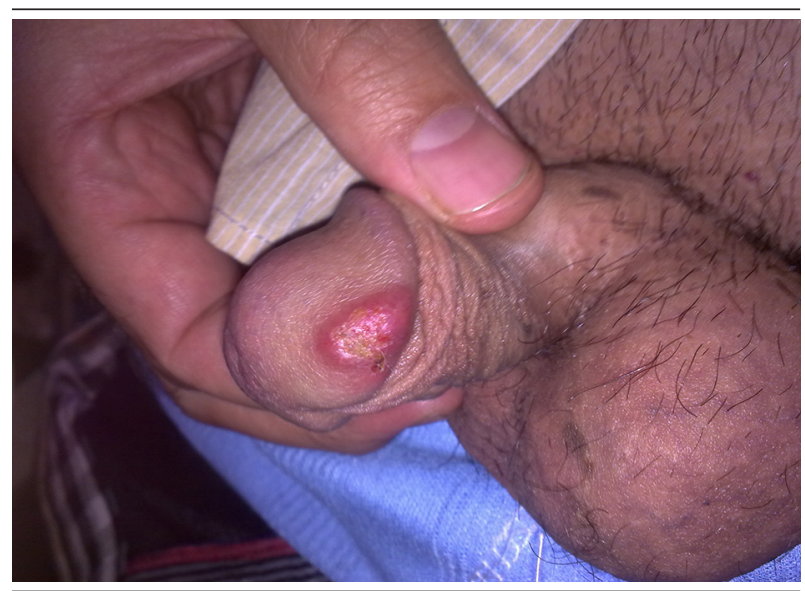

Figure 1. A Solitary, Erythematous, Indurated Plaque Measuring About 7 $\mathrm{mm} \times 13 \mathrm{~mm}$ Over the Lateral Aspect of Glans Penis

Copyright ( 2015, Skin and Stem Cell Journal. This is an open-access article distributed under the terms of the Creative Commons Attribution-NonCommercial 4.0 International License (http://creativecommons.org/licenses/by-nc/4.0/) which permits copy and redistribute the material just in noncommercial usages, provided the original work is properly cited. 
Figure 2. Thick-Walled Vessels in the Upper and Mid-dermis Lined by Plump Endothelial Cells Protruding Into the Lumen

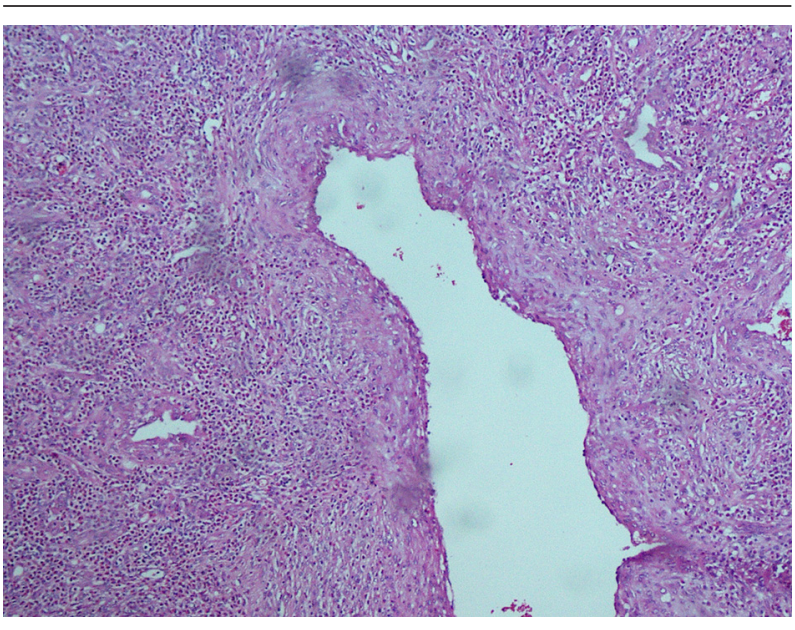

Hematoxylin and Eosin staining; magnification, 40×.

Figure 3. Relatively Dense Perivascular Lymphocytic Infiltrate With Many Eosinophils

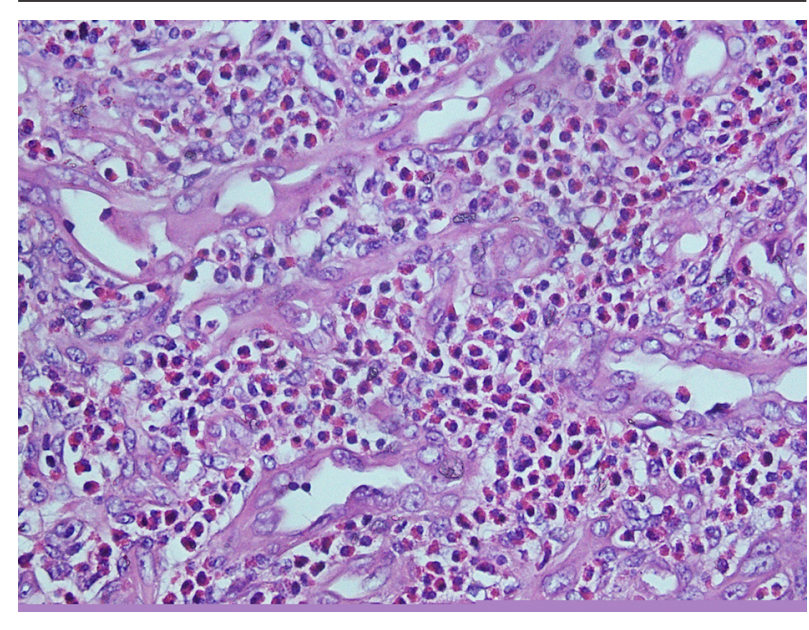

Hematoxylin and Eosin staining; magnification, 100×.

Findings of routine blood and biochemical tests and the chest X-ray were completely normal and results of screening tests for sexually transmitted infections including venereal disease research laboratory (VDRL) and viral markers such as hepatitis B virus (HBV), hepatitis $C$ virus (HCV), and human immunodeficiency virus (HIV) were negative.

According to the failure of therapeutic response to topical corticosteroid such as betamethasone ointment, a punch biopsy was performed that revealed unremarkable epidermis with large thick-walled vessels in the upper and mid dermis lined by plump endothelial cells protruding into the lumen (Figure 2). There was a relatively dense perivascular lymphocytic infiltrate with many eosinophils (Figure 3). These features were consistent with angiolymphoid hyperplasia. Based on clinicopathologic correlation, a final diagnosis of ALHE was made. Unfortunately, patient did not accept to undergo any treatment.

\section{Discussion}

The ALHE is a rare benign vascular proliferation presenting as dome-shaped papules and nodules in dermis and subcutaneous tissue. It is commonly found in the head and neck with most of the lesions being presented on peri-auricular region, forehead, or $\operatorname{scalp}(5,7,8)$. Involvement of other organs including liver, orbit, spleen, palate, bone, heart, blood vessels, parotid gland, and colon have been reported $(5,7)$. They may be asymptomatic or present as pulsatile, pruritic, or even painful lesions (6, 7). It is slightly more common in females, presenting between third to fifth decades of life, with mean age at onset of 30 to 33 years $(5,6)$; therefore, female hormones may play a role in the pathogenesis of ALHE. Peripheral blood eosinophilia ( $5-15 \%$ WBCs) is seen in about $20 \%$ of patients $(5,6)$. the ALHE is usually seen in Asians (5).

The first case of ALHE was described in 1969. The etiology is unknown. The studies have explained that ALHE is not neoplastic, but it is a form of reactive hyperplastic process that may develop as a result of injury and repair of vessels (5). Trauma, pregnancy, immunizations, and malformations may be the triggering factors for $\operatorname{ALHE}(3,5,7)$. Allergic reaction secondary to the immunization may induce ALHE lesions (5). Vascular endothelial growth factor and interleukin 5 are increased in some cases (5). In addition, ALHE may be a true vascular disorder, because some reports have described clonality in some ALHE lesions (3).

The clinical differential diagnosis includes lymphoid hyperplasia, lymphoma cutis, sarcoidosis, cutaneous metastases, Kaposi sarcoma, angiosarcoma, epithelioid hemangioendothelioma, and a reaction to insect bite $(3,7)$.

Histopathologic features of ALHE are characterized by proliferation of small- to medium-sized blood vessels, often with lobular architecture. These vessels are lined by plump epithelioid endothelial cells causing poorly canalized; the endothelial cells protrude into the lumen of the vascular channels and form a characteristic "cobblestone" appearance. The perivascular region is infiltrated by lymphocytes and eosinophils $(2,8)$. The number of mast cells is commonly increased in ALHE (1). The endothelial cells are homogeneously positive for CD34 (2). Immunohistochemical examination shows lymphocytes infiltration in ALHE lesions, which are large aggregation of $T$ cells and occasionally small infiltration of B cells that usually form the lymphoid follicles $(2,3)$; however, wellformed lymphoid aggregation are infrequently observed in ALHE (2).

The histopathologic differential diagnosis includes other vascular tumors, angiosarcoma, bacillary angiomatosis, and epithelioid hemangioendothelioma (9). The ALHE can remit in some cases after several months ( 3 , 5). Complete surgical excision is the treatment of choice, 
but recurrences have been reported in $33-50 \%$ of cases (1, $2,9)$. The recur is more reported after a partial surgical excision (4). Other treatment options include intralesional and systemic corticosteroids $(1,9)$ ablative and non-ablative lasers such as $\mathrm{CO}_{2}$ and pulsed dye laser, electrodessication, embolization, cytotoxic chemotherapy, radiation, and cryotherapy $(1,2,5)$.

To our knowledge, genitalia is a rare site of presentation for ALHE. Therefore, when there is any dermal or subcutaneous lesion, even on genitalia such as glans penis, it is logical to consider ALHE in differential diagnosis.

\section{Author's Contributions}

Study concept and design: Farhad Malekzad. Drafting the manuscript: Safoura Shakoei and Maryam Ranjbar. Critical revision of the manuscript for important intellectual content: all of the authors. Histopathologic examination: Kambiz Kamyab.

\section{Funding/Support}

This study was supported financially by Skin Research Center, Shahid Beheshti University of Medical Sciences, Tehran, IR Iran.

\section{References}

1. Satpathy A, Moss C, Raafat F, Slator R. Spontaneous regression of a rare tumour in a child: angiolymphoid hyperplasia with eosinophilia of the hand: case report and review of the literature. $\mathrm{Br} J$ Plast Surg. 2005;58(6):865-8.

2. Park Y, Chung J, Cho CG. Angiolymphoid hyperplasia with eosinophilia of the tongue: report of a case and review of the literature. Oral Oncol. 2002;38(1):103-6.

3. Guinovart RM, Bassas-Vila J, Morell L, Ferrandiz C. Angiolymphoid hyperplasia with eosinophilia: a clinicopathologic study of 9 cases. Actas Dermosifiliogr. 2014;105(2):e1-6.

4. Ueda S, Goto H, Usui Y, Nagai T, Nagao T. Angiolymphoid hyperplasia with eosinophilia occurring in bilateral eyelids. BMC Ophthalmol. 2013;13(1):38.

5. Trindade F, Haro R, Requena L. Giant angiolymphoid hyperplasia with eosinophilia on the chest. J Cutan Pathol. 2009;36(4):493-6.

6. Villanueva Pena A, de Diego Rodriguez E, Gomez Ortega JM, Hernandez Castrillo A, Lopez Rasines G. [Considerations about angiolymphoid hyperplasia with eosinophilia (ALHE) with regard to a case localized in the penis]. Actas Urol Esp. 2005;29(1):113-7.

7. Stewart N, Zagarella S, Mann S. Angiolyphoid hyperplasia with eosinophilia occurring after venipuncture trauma. J Dermatol. 2013;40(5):393-5.

8. Mankekar G, Chainani GN, Bhatt C, Sha TM. Angiolymphoid hyperplasia with eosbvophilia-case report. Indian J Otolaryngol Head Neck Surg. 2000;52(2):167-8.

9. Kurihara Y, Inoue H, Kiryu H, Furue M. Epithelioid hemangioma (angiolymphoid hyperplasia with eosinophilia) in zosteriform distribution. Indian J Dermatol. 2012;57(5):401-3. 